\title{
Plant and human aquaporins: pathogenesis from gut to brain
}

\author{
Jama Lambert ${ }^{1}$ - Soledad Mejia ${ }^{1}$ - Aristo Vojdani ${ }^{2,3}$ \\ Published online: 19 December 2018 \\ (C) The Author(s) 2018
}

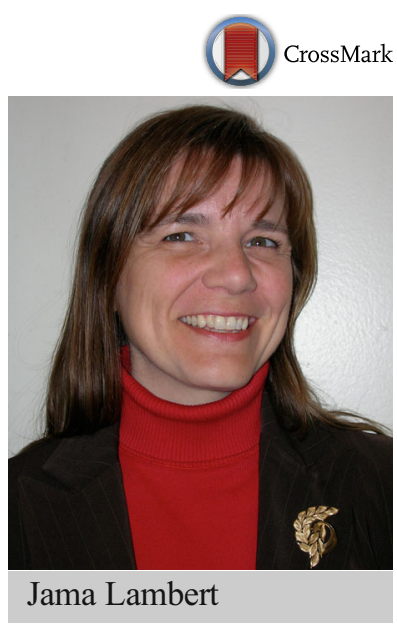

\begin{abstract}
Corn, soybean, spinach leaf, and tomato aquaporins have been shown to share homology with human aquaporin-4, which is abundantly expressed by brain astrocytic endfeet. Thus, antibodies formed against the dietary aquaporins may potentially cross-react with brain aquaporin, leading to blood-brain barrier permeability and setting the stage for neuroautoimmunity and neurodegeneration. Here, we review the role of aquaporins in plants and humans in maintaining a healthy organism and mechanisms by which dietary aquaporins may contribute to neurological disorders. We include clinical data on the correlation between four real-world, dietary aquaporin and five neurological tissue antibodies. Our findings showed the percent of neurological tissue antibody production increased with the number of positive food aquaporins. Of the four food aquaporins, spinach was the most common reactive. Of the neurological tissues assessed, tubulin was the most common positive. Patients with antibody reactivity to dietary aquaporins may consider abstaining from the aquaporin-containing food in order to prevent neurological tissue damage.
\end{abstract}

Keywords Aquaporin · Corn · Soybean · Spinach · Tomato $\cdot$ Neuroautoimmunity

\section{Introduction}

Neurological disorders including Alzheimer's disease, multiple sclerosis, and autism spectrum disorders are devastating, not only to the patient but also to the family and loved ones of the afflicted. Any simple lifestyle choices that could prevent the onset of neuroautoimmunity should be investigated. Diet is a controllable lifestyle choice. The identification of offending foods can play a role in the prevention or arrest of neuroautoimmune reactivity.

Jama Lambert

J.Lambert@CyrexLabs.com

Cyrex Laboratories, LLC, 2602 S. 24th St, Phoenix, AZ 85034, USA

2 Immunosciences Lab, Inc, 822 S. Robertson Blvd, Ste 312, Los Angeles, CA 90035, USA

3 Department of Preventive Medicine, Loma Linda University, Loma Linda, CA 92350, USA
Specific foods have been shown to play a role in certain neurological disorders. Indeed, nutrition and dietary strategies are being investigated or recommended for Alzheimer's disease [1-3], multiple sclerosis [4-6], and autism spectrum disorders [7-9]. In a previous study [10], we demonstrated the correlation between the production of gluten-family protein, dairy-family protein, and lectin/agglutinin antibodies and the reactivity to self-tissues. The number one targeted tissue for each food group antibodies was neurological.

One of the major components protecting the nervous system is the astrocytes. Using its endfeet, which express an aquaporin (AQP), one of the astrocyte's roles is the support of the blood-brain barrier (BBB). Due to the antigenic similarity between plant and human AQPs, antibody immune reaction against food-based AQP can result in neuroautoimmunity. Circulation of these food AQP antibodies alone may not result in autoimmune disease, but a breach of the $\mathrm{BBB}$ allows for these, and other circulating pathogenic antibodies, to enter the nervous system and induce neuroautoimmuity. AQPs have been studied extensively in neuromyelitis optica [11-15]. Here, we review the functions and similarities of food and human aquaporins, 
the role of human aquaporin in the protection of the brain and nervous system, and the neuroautoimmunity that can occur when the blood-brain barrier has been breached.

\section{Aquaporin functions}

Moving water is the fundamental life-giving force on Earth. Without it, every living thing would perish. While life-giving, too much water can bring death. Most living terrestrial beings have aquaporin within them. AQP regulates the flow of water into, or out of, the organism, in order to optimize the wellbeing of the life form.

Aquaporins (AQPs) are membrane channel proteins $[16,17]$. They were first identified in soybean [18] as transporters of water, thus the name; however, later research found that these channel proteins facilitate the transport of boron, silicon, or carbon dioxide [16,17]. Thus, in plant research, the term aquaporin has been replaced with major intrinsic proteins (MIPs) to embrace the array of transported substrate necessities [16]. AQP is expressed in roots and leaves of many plants in order to take in water when needed. In times of drought, the aquaporin channels in the leaves are closed to transpiration, in order to conserve water [17]. Conversely, when too much water is in the soil, the root-based AQP channels are closed to the intake of water.

Like plants, humans have AQP water channel proteins. The first, aquaporin 1 (AQP1), was discovered in 1992 [19]. The human aquaporin often researched in neurological disorders is aquaporin 4 (AQP4). It is the most abundant water channel protein in the nervous system and plays an important role in BBB defense. Although AQP4 is concentrated in the astrocytic foot process, it is also expressed, at lower concentrations, in other organs including the lung, thyroid, and stomach [20-22]. In the brain, AQP4 plays a role in neuroplasticity [23], the removal of waste from the brain [24], and the control of water into and out of the brain [25]. Indeed, the expression of AQP4 is greatly increased during cognitive stimulation, showing that it plays a positive role in neuroplasticity [23]. AQP4 serves as a trash chute for the removal of waste out of the brain and into circulation, where it can be processed and eliminated from the body [23]. And, as the name implies, AQP4 transports water into the brain but also moves water out of the brain in times of edema [25].

Bestowed with a variety of protective properties, AQPs are vital to maintaining the health of the living being.

\section{Plant and human aquaporin homology}

Vaishnav and colleagues [26] did an elegant job of identifying the shared amino acid sequences of human and plant AQPs. Corn (maize), soybean, spinach leaf, and tomato AQPs have homology to AQP4 (Fig. 1). Shared structural homology between dietary proteins and human tissues can result in autoimmune reactivity in genetically susceptible individuals. Due to a similarity in structure, if antibodies are produced against a dietary protein, such as spinach leaf AQP, those spinach leaf AQP antibodies could potentially mistake AQP4 in the astrocytes for spinach leaf AQP. This mechanism of cross-reactivity, instigated by a dietary protein, and igniting an attack on self-tissue, as if it were foreign material, is illustrated in Fig. 2.

Cross-reactivity between dietary AQPs and AQP4 is concerning. Antibodies made against food AQPs were shown to react to AQP4 in patients with neuromyelitis optica (NMO) a subtype of multiple sclerosis (MS) [26]. Dietary AQPs are resilient. They can withstand dramatic temperature changes involved in food preparation, surviving the cooking process [27]. Therefore, food AQPs reach the gastrointestinal (GI) system as whole proteins. If they are antigenic to the consumer, antibodies will be formed. As discussed, these antibodies may attack self-tissue. Being that AQP4 is also expressed in the stomach [27], the ingestion of corn, soy, spinach, and tomato may even contribute to GI barrier breakdown.

A breakdown of the GI barrier allows for the rapid transport of large, antigenic material from foods, bacteria, and other gutrelated proteins, into circulation. Antibody formation follows. Excessive antibody production may lead to systemic inflammation, followed by autoimmunity as circulating antibodies may cross-react with self-tissues. A broken GI barrier has been shown to put the body at risk for autoimmunity [28-30]. Systemic inflammation and autoimmune reactivity may target the BBB, putting the brain and nervous system at risk for neuroautoimmune reactivity. The connection between the breakdown of the gut barrier leading to the breakdown of the BBB has been established [31-35].

\section{Human aquaporin and the blood-brain barrier}

Our focus on AQP4 centers on its vital support of the BBB. The BBB serves as a physical barrier between the brain and the circulating blood. Its structure is formed by the arrangement of endothelial cells and tight junctions that line the capillaries, which supply blood to the brain. It is a highly selective barrier that restricts the movement of all soluble proteins greater than $400 \mathrm{Da}$ from the blood across to the brain. Acting like a sieve, the BBB protects the brain from dietary antibodies, the products of enteric organisms such as lipopolysaccharides (LPSs), and toxic chemicals, etc., that circulate in the blood. The BBB naturally permits the passage of essential metabolites, small hydrophobic molecules like oxygen, carbon dioxide, hormones, etc.

On the brain side of the BBB, the barrier is enwrapped by the endfeet of astrocytes. By connecting their endfeet to the 


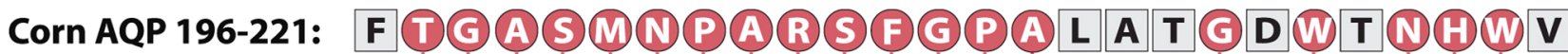

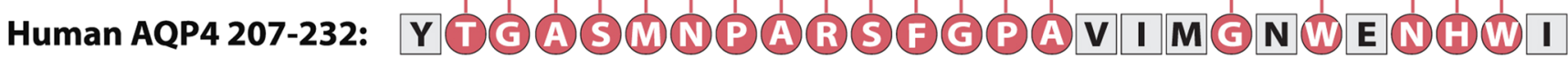

\title{
Soybean AQP 193-218: $F$ D A S MNPAV

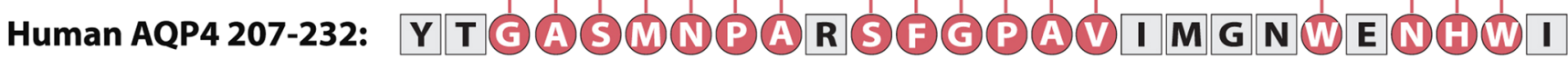

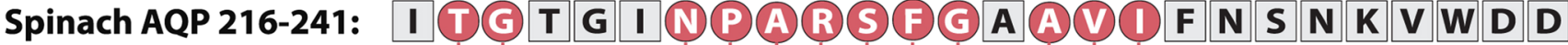

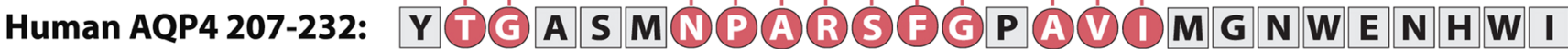

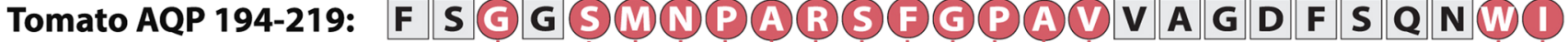

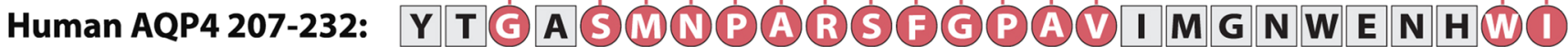

Fig. 1 Homology of human, corn, soybean, spinach and tomato aquaporins. Vaishnav and colleagues found incredible shared homology between sequences of human aquaporin and four specific food aquaporins

$\mathrm{BBB}$ endothelial cells and pericytes, astrocytes form a secondary layer of protection $[36,37]$. A breach of the BBB can occur due to a variety of environmental insults including emotional stress [38], systemic LPS [39, 40], repetitive head jarring as

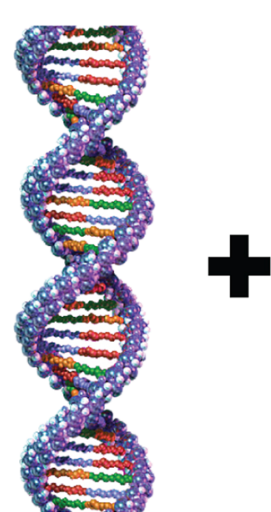

\section{Autoimmune} Gene

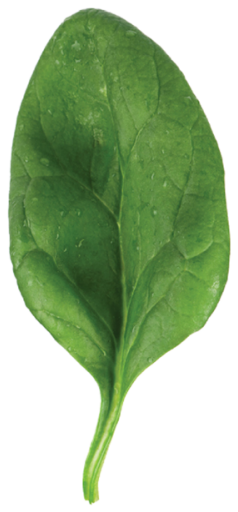

Spinach Aquaporin
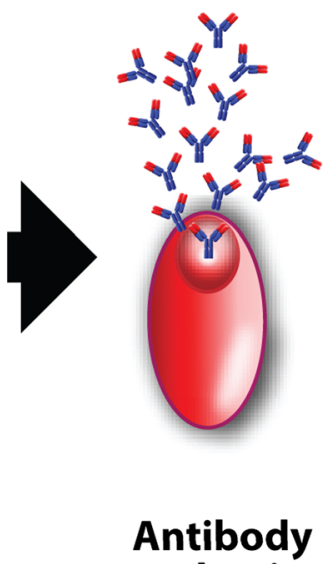
production against Spinach Aquaporin antigens

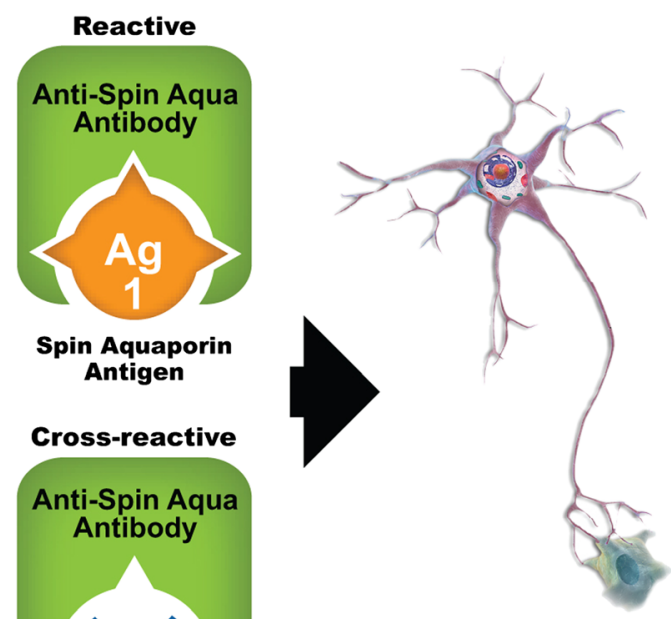

Neurological Autoimmunity

\section{Cross-reaction with AQP4 tissue antigen}

Fig. 2 Mechanism of food protein antibody cross-reactivity leading to neuroautoimmunity. The induction of environmentally-induced neuroautoimmunity by cross-reactivity or molecular mimicry starts with a genetic susceptibility for neurological disease. The person consumes spinach. The person loses immune tolerance to spinach aquaporin and makes a myriad of antibodies to aquaporin proteins. Some of those spinach aquaporin-specific antibodies mistake human aquaporin (AQP4) tissue for spinach aquaporin, attack it, which breaks down the blood-brain barrier and eventually neuroautoimmunity ensues 
seen in some sports [41], traumatic brain injury [42] as seen in motor vehicle accidents, concussions, and other physical impacts. The astrocyte structure must be secure in the event of a break in the $\mathrm{BBB}$, to provide a secondary barrier. However, this leaves no protection for the astrocytic endfeet. Due to the concentrated expression of AQP4 in the endfeet of astrocytes, they are vulnerable to circulating food AQP antibodies.

If antibodies against corn, soy, spinach, or tomato AQPs are circulating in the bloodstream during a breach of the BBB, those antibodies may attack AQP4 and thereby destroy the secondary layer of protection for the brain. AQP immunoglobulin (Ig) G was shown to compromise astrocytic endfoot integrity $[43,44]$. The result was a broken $\mathrm{BBB}$, dysfunction of synaptic microenvironments, and autoimmune astrocytopathies. See Fig. 3.

In pathogenesis, AQP4 plays a role in astrogliosis and the secretion of proinflammatory cytokines [40]. AQP4 has the distinction of being a target of autoimmunity in the pathogenesis of astrogliosis or NMO spectrum disorders [26, 45, 46].
Here, AQP4 antibodies bind to astrocytes contributing to the pathogenesis of NMO and related disorders [47]. Furthermore, AQP4 antibody levels were shown to increase previous to disease relapse [48], which supports the role of AQP4 antibodies as a mechanism of pathogenesis. NMO is more commonly found in Asian countries. It is speculated that this phenomenon occurs due to the increased consumption of soybean and spinach by these populations [26]. Neuropsychiatric disorders related to AQP4, as accumulated in an excellent review by Xiao and $\mathrm{Hu}$ [49], include Alzheimer's disease [50], depression [51], drug addiction [52], and Parkinson's disease [53].

\section{Consequence of BBB breakdown and entry of dietary protein antibodies into the nervous system}

When the BBB is damaged, it provides an unguarded entryway for environmental triggers to infiltrate the brain and

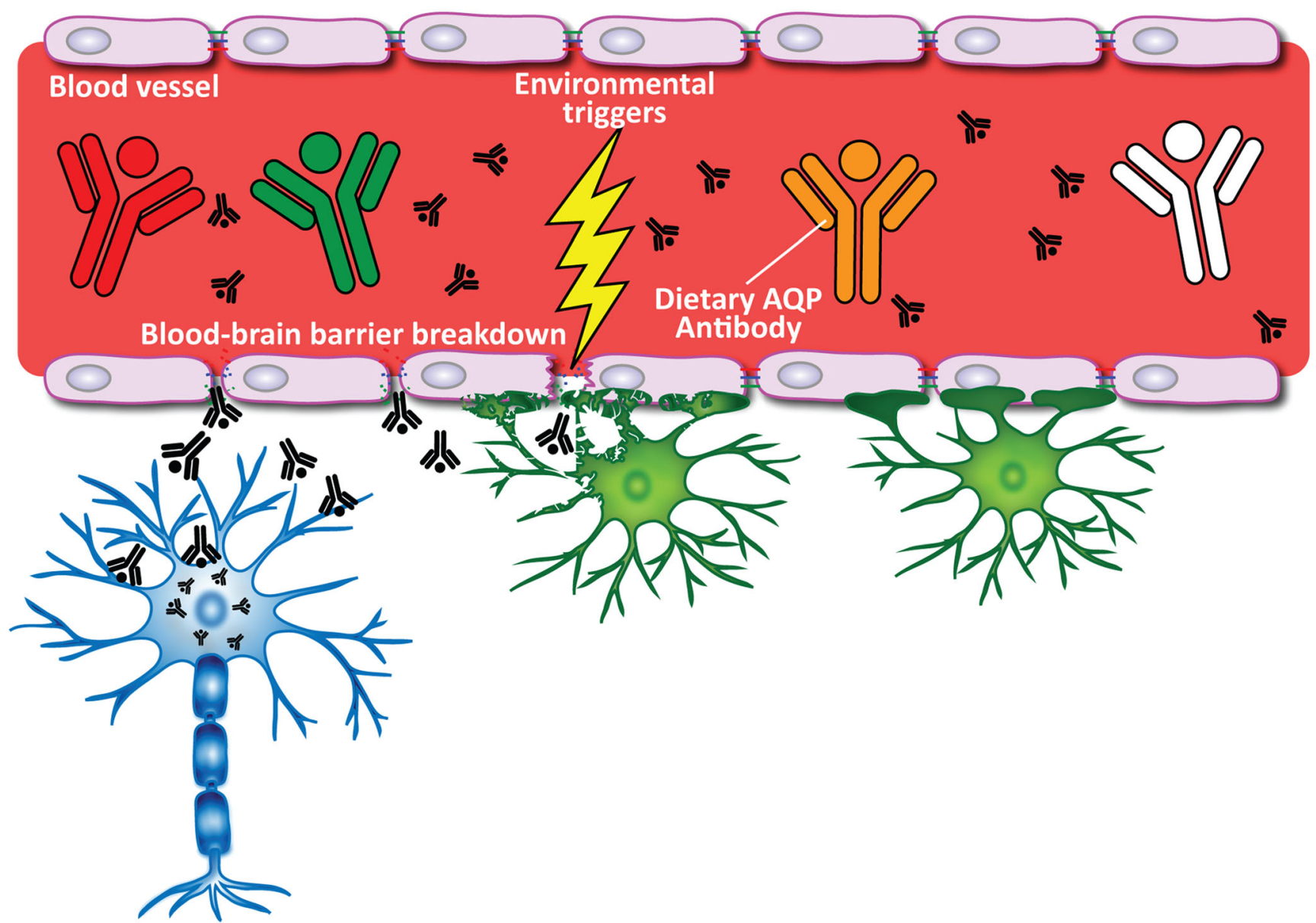

Fig. 3 Circulating autoreactive antibodies and break down of BBB. As long as the BBB is intact, the brain and nervous system are protected, even if there are multiple antibodies in the blood stream. A breach of the $\mathrm{BBB}$ via physical or emotional stressors allows dietary AQP antibodies (large antibodies) access to the astrocytic foot process. Once the foot process is destroyed, the breakdown of the BBB is complete. Any circulating antibodies (small antibodies) can now infiltrate the brain and target neurological tissues that are similar to the antibody's specific target antigen 
nervous system. As illustrated in Fig. 2, due to the similarity between some of these triggers and neurological tissues, neuro-reactive antibodies can be formed. The greater the number of circulating autoreactive antibodies during a breach of the $\mathrm{BBB}$, the greater the potential damage to the nervous system. As neuronal tissues become damaged, their entry into circulation ignites antibody production against self-tissue. Neuronal autoantibodies contribute to the onset of neurological diseases.

Known cross-reactions between neurological tissues and environmental triggers include a variety of food proteins and pathogens. The glycosphingolipid, asialoganglioside, has been shown to have cross-reactivity with gliadin [54], Campylobactor jejuni lipopolysaccharides [55], and streptococcal proteins [56]. Cerebellar neurons, called Purkinje cells, have been shown to have cross-reactivity with gliadin [54, 57] and milk butyrophilin [57]. Nerve sheath tissue, myelin basic protein, has been shown to be cross-reactive with gliadin [54], Chlamydia pneumoniae [58], herpes-6 [58], and streptococcal protein [58, 59]. Myelin sheath adhesion molecule, myelin oligodendrocyte glycoprotein, has been shown to cross-react with milk butyrophilin [57]. Synapsin, a regulator of neurotransmitter release, has been shown to have cross-reactivity with gliadin [54]. And finally, the building block protein, tubulin, has been shown to cross-react with streptococcal protein [59].

Neurological disorders associated with antibodies against the above-cited self-tissues include autism [60, 61], chronic inflammatory demyelinating polyneuropathy [62], demyelinating diseases [63, 64], gluten ataxia [57, 61], Guillain Barré syndrome [55], inhibited neurotransmitter release [65], Miller Fisher syndrome [55], motor neuron disease $[62,66]$, multifocal motor neuropathy [43], multiple sclerosis [58, 64, 66, 67], myasthenia gravis [66], pediatric autoimmune neuropsychiatric disorders associated with streptococcal infections (PANDAS) [59], paraneoplastic cerebellar degeneration syndrome $[57,68$, 69], and sensorimotor neuropathy [62]. A host of neurological disorders is possible if the BBB is broken.

The question of the chicken or the egg was posed by Vojdani et al., in a study of specific antibody production in patients with multiple sclerosis [70]. They found elevated serum antibodies to both human and plant AQPs. The authors speculate on the known cross-reactivity between human AQP4 and AQP from corn, soybean, spinach, and tomato, asking are the plant aquaporin antibodies elevated because the BBB has been breached and human aquaporin antibodies are cross-reacting with the food $A Q P S$, or were circulating plant AQPs attacking human aquaporin once the BBB was broken and astrocyte endfeet were exposed? Either scenario is possible.

In the first scenario, astrocytic endfeet are damaged, releasing AQP4 into the blood stream. Antibodies against AQP4 are formed. The innocuous plant AQPs consumed may be targeted by the AQP4 antibodies. This is a display of human AQP4 mistaking, or cross-reacting with, plant AQPs. The second scenario occurs when the initial antibody immune reaction was against ingested food AQPs. AQP antibodies circulate in the bloodstream. Once a breach of the BBB occurs, these circulating AQP antibodies mistake human AQP4 for food AQP and attack the self-tissue. This is food protein antibody cross-reactivity with human tissue protein.

\section{Correlation of dietary aquaporin and nervous system tissue antibodies}

If food AQP antibodies contribute to the breakdown of the $\mathrm{BBB}$, the presence of these antibodies should precede the onset of neuroautoimmune reactivity (Fig. 4). To better understand the risk of neuroautoimmunity in the presence of circulating antibodies against food aquaporins, we assessed IgG +
Fig. 4 Percent positive for neuroautoimmune reactivity. Figure shows percentage of individuals who tested positive for antibodies against at least one of five neurological tissue that reacted simultaneously to one food aquaporin $\square$, two food aquaporins $\boldsymbol{m}$, three food aquaporins $\Xi$, and four food aquaporins $\boldsymbol{\nabla}$ in males, females, and combined males and females

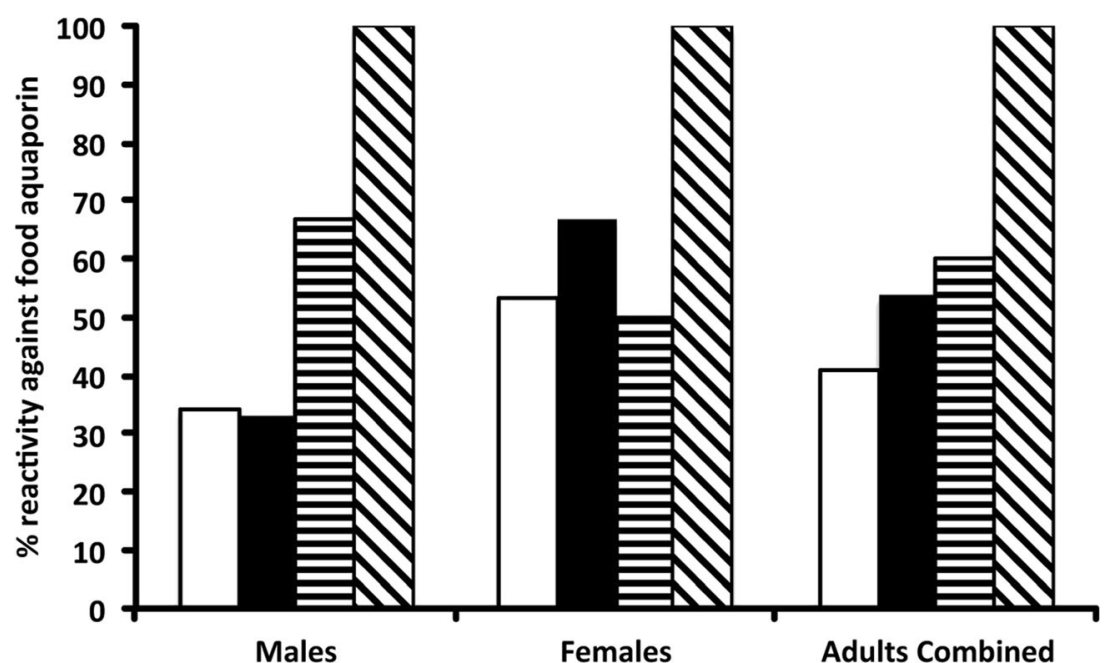


Fig. 5 Neurological tissue reactivity in patients with food aquaporin immune reactivity. Figure shows percentage of subjects reacting to myelin basic protein (MBP) $\square$,

asialoganglioside (GM1) $\mathbf{m}$, alpha

+ beta tubulin $\boldsymbol{\theta}$, cerebellar $\mathbf{Q}$ and synapsin $\boldsymbol{\nabla}$. These patients reported at least one food aquaporin positive. Adult females showed the most reactivity to selftissues. The most common reactivity, when combining all results, was to tubulin

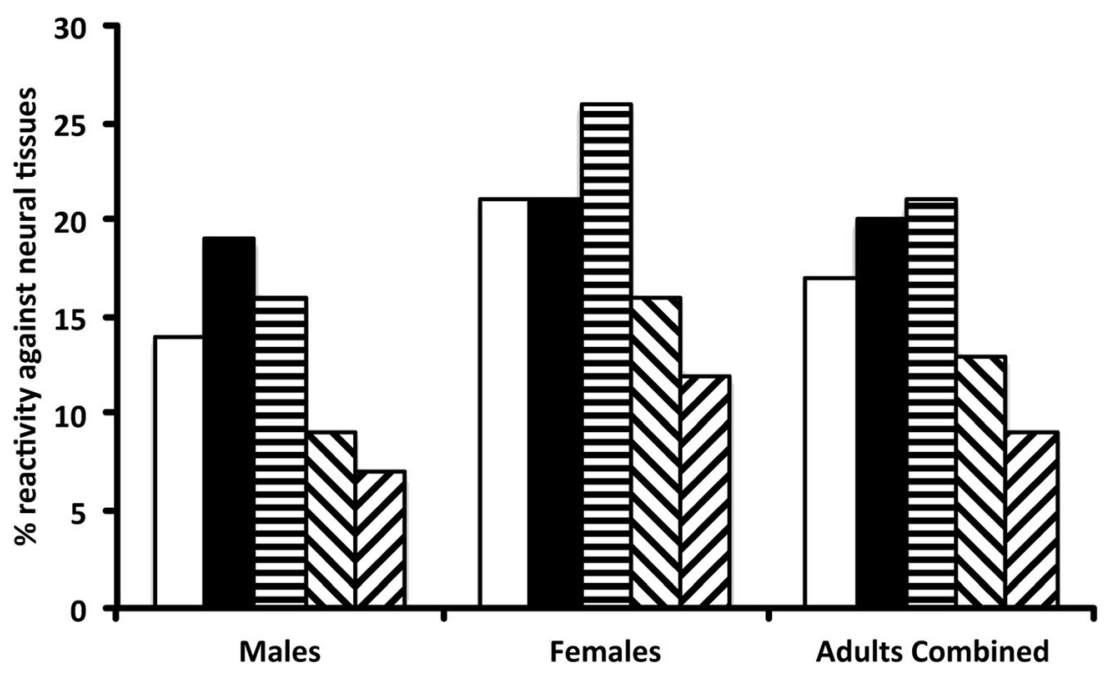

IgA immune reactivity against real-world dietary exposures of cooked corn + corn aquaporin, soybean oleosin + soy aquaporin, raw spinach + spinach aquaporin, and raw tomato + tomato aquaporin, simultaneously with $\mathrm{IgG}+\mathrm{IgA}$ immune reactivity against asialoganglioside, cerebellar, myelin basic protein, alpha + beta tubulin, and synapsin.

Testing was performed by Cyrex Laboratories, LLC, Phoenix, Arizona USA. Enzyme-linked immunosorbent assay technology, as previously described [52], was used for all assessments. Specimens were run in duplicate to ensure reproducibility of the results. Variations in optical density (OD) between duplicate wells were less than $20 \%$.

When 577 patients were assessed simultaneously for food and neuronal tissue reactivity, a total of 136 adult (19 years or older) subjects tested positive for at least one food + aquaporin (Fig. 5). We randomly selected 86 (43 male and 43 female) for gender comparison. We then compared the food testing results of these 86 individuals with their tissue antibody results.

The most reactive food containing aquaporin reactivity was spinach (79\%), followed by corn (64\%), tomato (37\%), and soybean $(26 \%)$. Variations were seen in results between adult males (ages 19-77) and females (ages 19-74). In males reacting to $1,2,3$, or 4 food aquaporins, $34 \%, 33 \%, 67 \%$, and $100 \%$ respectively reacted to one or more neurological tissues. While in females reacting to $1,2,3$, or 4 food aquaporins, $53 \%, 67 \%, 50 \%$, and $100 \%$ respectively reacted to one or more neurological tissues. However, the combined adult results revealed an increase in neurological autoimmune reactivity with an increase in the number of positive reactions to food aquaporin antigens. In adults reacting to 1, 2, 3, or 4 food aquaporins, $41 \%, 54 \%, 60 \%$, and $100 \%$ respectively reacted to one or more neurological tissues.

Females had more reactivity to neurological tissues than males. Results showed MBP (14\% males, $21 \%$ females), asialoganglioside (19\% males, $21 \%$ females), alpha + beta tubulin (16\% males, $26 \%$ females), cerebellar (9\% males,
$16 \%$ females), and synapsin ( $7 \%$ males, $12 \%$ females). Combined results revealed the most to the least common neuronal tissue reactivity as alpha + beta tubulin $(21 \%)$, asialoganglioside (20\%), myelin basic protein (17\%), cerebellar (13\%), and synapsin (9\%).

Clearly, the more reactivity to multiple food AQPs, the greater the possibility for neuroautoimmune reactivity. However, even a $41 \%$ chance for immune reactivity to selftissue, as seen in the adult reactivity to one food AQP, is significant, especially in patients with a family history of neurological disorders.

\section{Conclusion}

The known cross-reactivity between human AQP4 and corn, soybean, spinach leaf, and tomato AQPs, coupled with the knowledge that a broken BBB is the invitation for neuroautoimmunity, leads to two conclusions. First, if a healthcare practitioner is working with a patient who exhibits neurological symptoms, testing for food AQPs is warranted. A positive result, followed by the removal of the offending foods, may improve the patient's clinical condition. Second, if a patient shows reactivity to food AQPs, specifically corn, soybean, spinach, and/or tomato, follow up antibody testing of BBB integrity and neuronal tissues should be considered. If BBB dysfunction and/or neuroautoimmune reactivity is detected, a lifestyle dietary change that includes the avoidance of the specific AQP foods may prevent, slow down, or arrest the pathogenesis of neurodegeneration. A small number of patients were included in this study. Larger studies on food AQP and other food proteins that mimic neuronal tissues need to be performed to better understand the role of food in the pathogenesis of neurological disorders. 
Acknowledgments The authors wish to thank Thomas Berube and Joel Bautista for their assistance with the figures included in this article.

\section{Compliance with ethical standards}

Conflict of Interest The testing was performed by Cyrex Laboratories, LLC for which Jama Lambert works.

Open Access This article is distributed under the terms of the Creative Commons Attribution 4.0 International License (http:// creativecommons.org/licenses/by/4.0/), which permits unrestricted use, distribution, and reproduction in any medium, provided you give appropriate credit to the original author(s) and the source, provide a link to the Creative Commons license, and indicate if changes were made.

Publisher's note Springer Nature remains neutral with regard to jurisdictional claims in published maps and institutional affiliations.

\section{References}

1. Lange KW, Lange KM, Makulska-Gertruda E, Nakamura Y, Reissmann A, Kanaya S, et al. Ketogenic diets and Alzheimer's disease. Food Sci Human Wellness. 2017;6:109. https://doi.org/ 10.1016/j.fshw.2016.10.003.

2. Barnard ND, Bush AI, Ceccarelli A, Cooper J, de Jager CA, Erickson KI, et al. Dietary and lifestyle guidelines for the prevention of Alzheimer's disease. Neurobiol Aging. 2014;35(Suppl 2): S74-8. https://doi.org/10.1016/j.neurobiolaging.2014.03.033.

3. Gasior M, Rogawski MA, Hartman AL. Neuroprotective and disease-modifying effects of the ketogenic diet. Behav Pharmacol. 2006;17(5-6):431-9.

4. Riemann-Lorenz K, Eilers M, von Geldern G, Schulz KH, Köpke $\mathrm{S}$, Heesen C. Dietary interventions in multiple sclerosis: development and pilot-testing of an evidence based patient education program. PLoS One. 2016;11(10):e0165246. https://doi.org/10.1371/ journal.pone. 0165246 .

5. Saresella M, Mendozzi L, Rossi V, Mazzali F, Piancone F, LaRosa $\mathrm{F}$, et al. Immunological and clinical effect of diet modulation of the gut microbiome in multiple sclerosis patients: a pilot study. Front Immunol. 2017;8:1391. https://doi.org/10.3389/fimmu.2017. 01391.

6. Esposito S, Bonavita S, Sparaco M, Gallo A, Tedeschi G. The role of diet in multiple sclerosis: a review. Nutr Neurosci. 2017;24:1-14. https://doi.org/10.1080/1028415X.2017.1303016.

7. Herbert MR, Buckley JA. Autism dietary therapy: case report and review of literature. J Child Neurol. 2013;28(8):975-82. https://doi. org/10.1177/0883073813488668.

8. Rubenstein E, Schieve L, Bradley C, DiGuiseppi C, Moody E, Thomas K, et al. The prevalence of gluten free diet use among preschool children with autism spectrum disorder. Autism Res. 2018;11(1):185-93. https://doi.org/10.1002/aur.1896.

9. Whiteley P, Shattock P, Knivsberg AM, Seim A, Reichelt KL, Todd $\mathrm{L}$, et al. Gluten- and casein-free dietary intervention for autism spectrum conditions. Front Hum Neurosci. 2013;6:344. https:// doi.org/10.3389/fnhum.2012.00344.

10. Lambert J, Vojdani A. Correlation of tissue antibodies and food immune reactivity in randomly selected patient specimens. J Clin Cellular Immunol. 2017;8(5). https://doi.org/10.4172/2155-9899. 1000521.

11. Wilson R, Makuch M, Kienzler A-K, Varley J, Taylor J, Woodhall $\mathrm{M}$, et al. Condition-dependent generation of aquaporin- 4 antibodies from circulating B cells in neuromyelitis optica. Brain. 2018;141: 1063-74. https://doi.org/10.1093/brain/awy010.

12. Matiello M, Schaefer-Klein JL, Hebrink DD, Kingsbury DJ, Atkinson EJ, Weinshenker BG. Genetic analysis of aquaporin-4 in neuromyelitis optica. Neurology. 2011;77(12):1149-55. https:// doi.org/10.1212/WNL.0b013e31822f045b.

13. Isobe N, Yonekawa T, Matsushita T, Masaki K, Yoshimura S, Fichna J, et al. Clinical relevance of serum aquaporin-4 antibody levels in neuromyelitis optica. Neurochem Res. 2013;38(5):9971001. https://doi.org/10.1007/s11064-013-1009-0.

14. Alves Do Rego C, Collongues N. Neuromyelitis optica spectrum disorders: Features of aquaporin-4, myelin oligodendrocyte glycoprotein and double-seronegative-mediated subtypes. Rev Neurol (Paris). 2018. https://doi.org/10.1016/j.neurol.2018.02.084.

15. Sepúlveda M, Sola-Valls N, Escudero D, Rojc B, Barón M, Hernández-Echebarría L, et al. Clinical profile of patients with paraneoplastic neuromyelitis optica spectrum disorder and aquaporin-4 antibodies. Mult Scler. 2017;1:1352458517731914. https://doi.org/10.1177/1352458517731914.

16. Li G, Santoi V, Maurel C. Plant aquaporins: roles in plant physiology. Biochim Biophys Acta. 2014;1840(5):1574-82. https://doi. org/10.1016/j.bbagen.2013.11.004.

17. Afzal Z, Howton TC, Sun Y, Mukhtar MS. The roles of aquaporins in plant stress responses. J Dev Biol. 2016;4(1):9. https://doi.org/ $10.3390 / j \mathrm{db} 4010009$.

18. Fortin MG, Morrison NA, Verma DPS. Nodulin-26, a peribacteroid membrane nodulin is expressed independently of the development of the peribacteroid compartment. Nucleic Acids Res. 1987;15(2): 813-24.

19. Preston GM, Carroll TP, Guggino WB, Agre P. Appearance of water channels in Xenopus oocytes expressing red cell CHIP28 protein. Science. 1992;256(5055):385-7.

20. Brown D, Katsura T, Kawashima M, Verkman AS, Sabolic I. Cellular-distribution of the aquaporins - a family of water channel proteins. Histochem Cell Biol. 1995;104(1):1-9.

21. Mobasheri A, Marples D, Young IS, Floyd RV, Moskaluk CA, Frigeri A. Distribution of the AQP4 water channel in normal human tissues - protein and tissue microarrays reveal expression in several new anatomical locations, including the prostate gland and seminal vesicles. Channels. 2007;1(1):29-38.

22. Laforenza $\mathrm{U}$. Water channel proteins in the gastrointestinal tract. Mol Asp Med. 2012;33(5-6):642-50. https://doi.org/10.1016/j. mam.2012.03.001.

23. Woo J, Kim JE, Im JJ, Lee J, Jeong HS, Park S, et al. Astrocytic water channel aquaporin- 4 modulates brain plasticity in both mice and humans: a potential gliogenetic mechanism underlying language-associated learning. Mol Psychiatry. 2018;23(4):102130. https://doi.org/10.1038/mp.2017.113.

24. Gleiser C, Wagner A, Fallier-Becker P, Hirt B, Mack AF. Aquaporin-4 in astroglial cells in the CNS and supporting cells of sensory organs: a comparative perspective. Int J Mol Sci. 2016;17(9):e1411. https://doi.org/10.3390/ijms17091411.

25. Badaut J, Fukuda AM, Jullienne A, Petry KG. Aquaporin and brain diseases. Biochim Biophys Acta. 2014;1840(5):1554-65. https:// doi.org/10.1016/j.bbagen.2013.10.032.

26. Vaishnav RA, Liu R, Chapman J, Roberts AM, Ye H, RebolledoMendez JD, et al. Aquaporin 4 molecular mimicry and implications for neuromyelitis optica. J Neuroimmunol. 2013;260(1-2):92-8. https://doi.org/10.1016/j.jneuroim.2013.04.015.

27. Plasencia I, Survery S, Ibragimova S, Hansen JS, Kiellbom P, Helix-Nielsen C, et al. Structure and stability of the spinach aquaporin SoPIP2;1 in detergent micelles and lipid membranes. PLoS One. 2011;6(2):e14674. https://doi.org/10.1371/annotation/ 589616b0-91e1-406c-8cf9-fe78ac08b8f6.

28. Bischoff SC, Barbara G, Buurman W, Ockhuizen T, Schulzke JD, Serino $\mathrm{M}$, et al. Intestinal permeability - a new target for disease 
prevention and therapy. BMC Gastroenterol. 2014;14:189. https:// doi.org/10.1186/s12876-014-0189-7.

29. Fasano A. Zonulin and its regulation of intestinal barrier function: the biological door to inflammation, autoimmunity, and cancer. Physiol Rev. 2011;91(1):151-75. https://doi.org/10.1152/physrev. 00003.2008 .

30. Nouri M, Bredberg A, Weström B, Lavasani S. Intestinal barrier dysfunction develops at the onset of experimental autoimmune encephalomyelitis, and can be induced by adoptive transfer of autoreactive T cells. PLoS One. 2014;9(9):e106335. https://doi.org/10. 1371/journal.pone.0106335.

31. Daneman R, Rescigno $M$. The gut immune barrier and the bloodbrain barrier: are they so different? Immunity. 2009;31:722-35. https://doi.org/10.1016/j.immuni.2009.09.012.

32. Houser MC, Tansey MG. The gut-brain axis: is intestinal inflammation a silent driver of Parkinson's disease pathogenesis? NPJ Parkinsons Dis. 2017;3:3. https://doi.org/10.1038/s41531-0160002-0.

33. Rogers GB, Keating DJ, Young RL, Wong ML, Licinio J, Wesselingh S. From gut dysbiosis to altered brain function and mental illness: mechanisms and pathways. Mol Psychiatry. 2016;21(6):738-48. https://doi.org/10.1038/mp.2016.50.

34. Savidge TC, Sofroniew MV, Neunlist M. Starring roles for astroglia in barrier pathologies of gut and brain. Lab Investig. 2007;87(8): 731-6. https://doi.org/10.1038/labinvest.3700600.

35. Vojdani A, Lambert J, Vojdani E. The gut-brain axis: autoimmune and neuroimmune disorders. Altern Ther Health Med. 2016;22(S3): $31-46$.

36. Cabezas R, Avila M, Gonzalez J, El-Bachá RS, Báez E, GarcíaSegura LM, et al. Astrocytic modulation of blood brain barrier: perspectives on Parkinson's disease. Front Cell Neurosci. 2014;8: 211. https://doi.org/10.3389/fncel.2014.00211.

37. Serlin Y, Shelef I, Knyazer B, Friedman A. Anatomy and physiology of the blood-brain barrier. Semin Cell Dev Biol. 2015;38:2-6. https://doi.org/10.1016/j.semcdb.2015.01.002.

38. Esposito P, Gheorghe D, Kandere K, Pang X, Connolly R, Jacobson $\mathrm{S}$, et al. Acute stress increases permeability of the blood-brainbarrier through activation of brain mast cells. Brain Res. 2001;888(1):117-27.

39. Arican N, Kaya M, Kalayci R, Uzun H, Ahishali B, Bilgic B, et al. Effects of lipopolysaccharide on blood-brain barrier permeability during pentylenetetrazole-induced epileptic seizures in rats. Life Sci. 2006;79(1):1-7. https://doi.org/10.1016/j.1fs.2005.12.035.

40. Xaio H, Banks WA, Niehoff ML, Morley JE. Effect of LPS on the permeability of the blood-brain barrier to insulin. Brain Res. 2001;896(1-2):36-42.

41. Vojdani A. Brain-reactive antibodies in traumatic brain injury. Funct Neurol Rehabil Ergon. 2013;3(2-3):173-81.

42. Chodobski A, Zink BJ, Szmydynger-Chodobska J. Blood-brain barrier pathophysiology in traumatic brain injury. Transl Stroke Res. 2011;2(4):492-516. https://doi.org/10.1007/s12975-0110125-x.

43. Hinson SR, Pittock SJ, Lucchinetti CF, Roemer SF, Fryer JP, Kryzer $\mathrm{TJ}$, et al. Pathogenic potential of IgG binding to water channel extracellular domain in neuromyelitis optica. Neurology. 2007;69(24):2221-31. https://doi.org/10.1212/01.WNL. 0000289761.64862.ce.

44. Hinson SR, Romero MF, Popescu BF, Lucchinetti CF, Fryer JP, Wolburg H, et al. Molecular outcomes of neuromyelitis optica (NMO)-IgG binding to aquaporin-4 in astrocytes. Proc Natl Acad Sci U S A. 2012;109(4):1245-50. https://doi.org/10.1073/pnas. 1109980108

45. Yang Y, Huang D-H, Wu W-P, Wu L, Chen LF, Wu Q. The role of aquaporin-4 antibodies in Chinese patients with neuromyelitis optica. J Clin Neurosci. 2013;20(1):94-8. https://doi.org/10.1016/ j.jocn.2012.06.006.
46. Lennon VA, Kryzer TJ, Pittock SJ, Verkman AS, Hinson SR. IgG marker of optic-spinal multiple sclerosis binds to the aquaporin-4 water channel. J Exp Med. 2005;202(4):473-7. https://doi.org/10. 1084/jem.20050304.

47. Waters P, Jarius S, Littleton E, Leite MI, Jacob S, Gray B, et al. Aquaporin-4 antibodies in neuromyelitis optica and longitudinally extensive transverse myelitis. Arch Neurol. 2008;65(7):913-9. https://doi.org/10.1001/archneur.65.7.913.

48. Jarius S, Aboul-Enein F, Waters P, Kuenz B, Hauser A, Berger T, et al. Antibody to aquaporin-4 in the long-term course of neuromyelitis optica. Brain. 2008;131(Pt 11):3072-80. https://doi.org/10. 1093/brain/awn240.

49. Xiao $\mathrm{M}, \mathrm{Hu} \mathrm{G}$. Involvement of aquaporin 4 in astrocyte function and neuropsychiatric disorders. CNS Neurosci Ther. 2014;20(5): 385-90. https://doi.org/10.1111/cns.12267.

50. Zeppenfeld DM, Simon M, Haswell JD, D'Abreo D, Murchison C, Quinn JF, et al. Association of perivascular localization of aquaporin-4 with cognition and Alzheimer disease in aging brains. JAMA Neurol. 2017;74(1):91-9. https://doi.org/10.1001/ jamaneurol.2016.4370.

51. Kong H, Sha LL, Fan Y, Xiao M, Ding JH, Wu J, et al. Requirement of AQP4 for antidepressive efficiency of fluoxetine: implication in adult hippocampal neurogenesis. Neuropsychopharmacology. 2009;34(5):1263-76. https://doi.org/10.1038/npp.2008.185.

52. Xie LL, Sun XL, Fan Y, Kong H, Ding JH, Hu G. Aquaporin 4 knockout resists negative regulation of neural cell proliferation by cocaine in mouse hippocampus. Int $\mathrm{J}$ Neuropsychopharmacol. 2009;12(6):843-50. https://doi.org/10.1017/S1461145709009900.

53. Chi Y, Fan Y, He L, Liu W, Wen X, Zhou S, et al. Novel role of aquaporin-4 in CD4+ CD25+ T regulatory cell development and severity of Parkinson's disease. Aging Cell. 2011;10(3):368-82. https://doi.org/10.1111/j.1474-9726.2011.00677.x.

54. Vojdani A, Tarash I. Cross-reaction between gliadin and different food and tissue antigens. Food Nutri Sci. 2013;4:20-32. https://doi. org/10.4236/fns.2013.41005.

55. Jacobs BC, Hazenberg MP, van Doorn PA, Endtz HP, van der Meché FG. Cross-reactive antibodies against gangliosides and Campylobacter jejuni lipopolysaccharides in patients with Guillain-Barré or Miller Fisher syndrome. J Infect Dis. 1997;175: 729-33.

56. Mertens NMJ, Galvin JE, Adderson EE, Cunningham MW. Molecular analysis of cross-reactive anti-myosin/anti-streptococcal mouse monoclonal antibodies. Mol Immunol. 2000;37(15):90113.

57. Vojdani A, O'Bryan T, Green JA, McCandless J, Woeller K, Vojdani E, et al. Immune response to dietary proteins, gliadin and cerebellar peptides in children with autism. Nutr Neurosci. 2004;7(3):151-61. https://doi.org/10.1080/10284150400004155.

58. Vojdani A, Vojdani E, Cooper E. Antibodies to myelin basic protein, myelin oligodendrocytes peptides, $\alpha$-B-crystallin, lymphocyte activation and cytokine production in patients with multiple sclerosis. J Internal Med. 2003;254(4):363-74.

59. Vojdani A. Obsessive compulsive disorder and differentiation between non-autoimmune OCD and the autoimmune version of the disease called PANDAS. Latitudes. 2003;6(2):1-6.

60. Ashwood P, Van de Water J. Is autism an autoimmune disease? Autoimmune Rev. 2004;3(7-8):557-62. https://doi.org/10.1016/j. autrev.2004.07.036.

61. Hadjivassiliou M, Boscolo S, Davies-Jones GA, Grünewald RA, Not T, Sanders DS, et al. The humoral response in the pathogenesis of gluten ataxia. Neurology. 2002;58(8):1221-6.

62. Bansal AS, Abdul-Karim B, Malik RA, Goulding P, Pumphrey RS, Boulton AJ, et al. IgM ganglioside GM1 antibodies in patients with autoimmune disease or neuropathy, and controls. J Clin Pathol. 1994;14:300-2. 
63. Howard MK, Gull K, Miles MA. Antibodies to tubulin in patients with parasitic infections. Clin Exp Immunol. 1987;68(1):78-85.

64. Bitsch A, Dressel A, Meier K, Bogumil T, Deisenhammer F, Tumani $\mathrm{H}$, et al. Autoantibody synthesis in primary progressive multiple sclerosis patients treated with interferon beta- $1 \mathrm{~b}$. J Neurol. 2004;251(12):1498-501. https://doi.org/10.1007/s00415004-0580-3.

65. Gitlits VM, Sentry JW, Matthew LS, Smith AI, Toh BH. Synapsin I identified as a novel brain-specific autoantigen. J Investig Med. 2001;49(3):276-83. https://doi.org/10.2310/6650.2001.33973.

66. Baba H, Daune GC, Ilyas AA, Pestronk A, Cornblath DR, Chaudhry V, et al. Anti-GM1 ganglioside antibodies with differing fine specificities in patients with multifocal motor neuropathy. J Neuroimmunol. 1989;25(2-3):143-50.

67. Berger T, Rubner P, Schautzer F, Egg R, Ulmer H, Mayringer I, et al. Antimyelin antibodies as a predictor of clinically definite multiple sclerosis after a first demyelinating event. $\mathrm{N}$ Engl Med. 2003;349(2):139-45. https://doi.org/10.1056/NEJMoa022328.

68. Balegno S, Ceroni M, Corato M, Franciotta D, Giometto B, Marinu-Aktipu K, et al. Antibodies to cerebellar nerve fibres in two patients with paraneoplastic cerebellar ataxia. Anticancer Res. 2005;25(5):3211-4.

69. Dropcho EJ, Chen YT, Posner JB, Old LJ. Cloning of a brain protein identified by autoantibodies from a patient with paraneoplastic cerebellar degeneration. Poc Natl Acad Sci U S A. 1987;84(13):4552-6.

70. Vojdani A, Mukherjee PS, Berookhim J, Kharrazian D. Detection of antibodies against human and plant aquaporins in patients with multiple sclerosis. Autoimmune Dis. 2015;2015:905208. https:// doi.org/10.1155/2015/905208. 